\title{
Transrectal endoscopic ultrasound in undiagnosed ascites: is it a peritoneal deposit?
}

A 38-year-old woman presented with abdominal distension of 2 months' duration. Ultrasound and computed tomography (CT) scans revealed ascites. Ascitic fluid analysis revealed exudative fluid, with non-elevated fluid adenosine deaminase and amylase values. Cytological examination of the ascitic fluid did not reveal malignant cells. No fluorodeoxyglucose-avid lesions were observed on positron emission tomography (PET) scanning, and no abnormality was observed on either gastroscopy or colonoscopy. A peritoneal evaluation was performed by endoscopic ultrasound (EUS); however, no peritoneal lesion was observed on EUS performed from the stomach and duodenum. Rectal EUS was therefore subsequently performed, which revealed pelvic ascites, along with a well-defined echogenic nodular lesion adjacent to the parietal peritoneum of the lateral pelvic wall that, on initial evaluation, appeared to be a peritoneal deposit ( $\mathbf{F i g} \mathbf{1} \mathbf{a}$ ). Careful anatomical evaluation revealed the lesion to be anterior to the internal iliac vessels. The lesion had a central echogenic area with a peripheral hypoechoic area, with cysts of varying sizes ( $>$ Fig. 1 b).

These morphological and anatomical features were suggestive of the left ovary. Careful evaluation also revealed a corpus luteum with echogenic contents ( $\triangleright$ Fig.1 c). No abnormal enhancing peri- toneal lesion was observed on contrastenhanced EUS (CEUS), but the wall of the corpus luteum was found to be hyperenhancing, suggestive of increased vascularity (> Fig. 2; Video 1).

On EUS, peritoneal deposits appear as echogenic rounded lesions surrounded

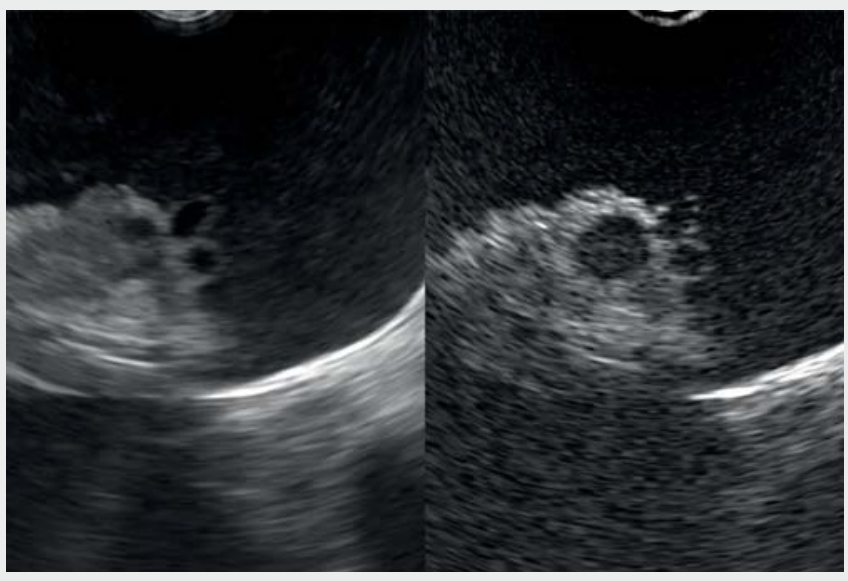

Video 1 Contrast-enhanced endoscopic ultrasound (CEUS) showing the echogenic lesion to be hypervascular, with the wall of the corpus luteum being hyperenhancing.
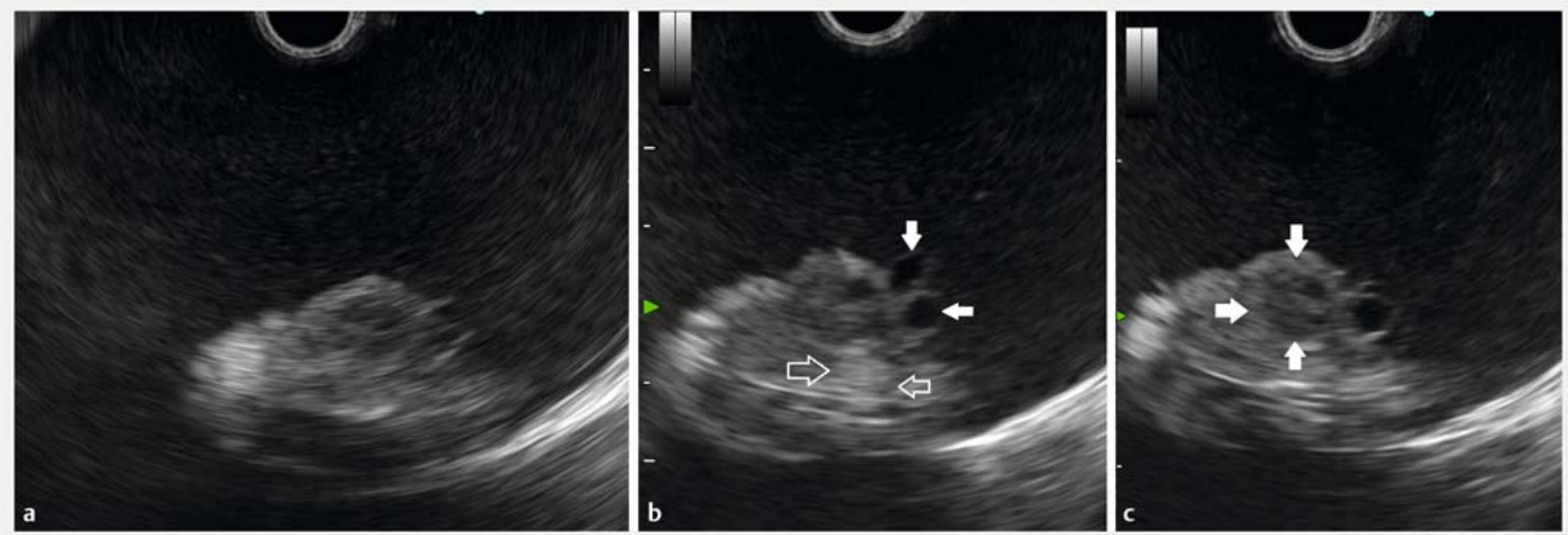

- Fig. 1 Rectal endoscopic ultrasound (EUS) images showing: a pelvic ascites, along with a well-defined echogenic nodular lesion adjacent to the parietal peritoneum of the lateral pelvic wall; $\mathbf{b}$ a central echogenic area (open arrows), with a peripheral hypoechoic area having cysts (white arrows) of varying sizes; $\mathbf{c}$ the ovary containing a corpus luteum with echogenic contents (arrows). 


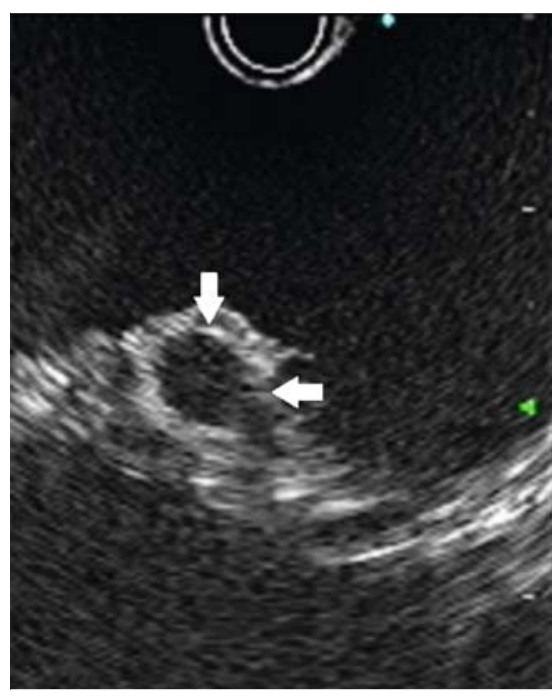

- Fig. 2 Contrast-enhanced endoscopic ultrasound (CEUS) showing that the wall of the corpus luteum was hyperenhancing, suggestive of increased vascularity.

by anechoic ascitic fluid [1,2]. They can be visualized from the upper gastrointestinal tract, as well as on rectal EUS [3]. In the current report, a normal ovary mimicked a peritoneal deposit. However, careful evaluation of the anatomical location, as well as the sonographic appearance with the presence of follicles can help in correct identification of the ovary. In the majority of pre- and postmenopausal women, the ovaries are located immediately adjacent to the internal iliac vessels [4].

Endoscopy_UCTN_Code_CCL_1AF_2AG_3AD

\section{Competing interests}

The authors declare that they have no conflict of interest.

\section{The authors}

Surinder S. Rana ${ }^{1}$, Nikhil Bush ${ }^{1}$, Rajesh Gupta ${ }^{2}$

1 Department of Gastroenterology, Postgraduate Institute of Medical Education and Research (PGIMER), Chandigarh, India

2 Department of Surgical Gastroenterology, Postgraduate Institute of Medical Education and Research (PGIMER), Chandigarh, India

Corresponding author

\section{Surinder S. Rana, MD}

Department of Gastroenterology, Postgraduate Institute of Medical Education and Research (PGIMER), Chandigarh 160012, India

drsurinderrana@yahoo.co.in

\section{References}

[1] Rana SS, Bhasin DK, Srinivasan R et al. Endoscopic ultrasound-guided fine needle aspiration of peritoneal nodules in patients with ascites of unknown cause. Endoscopy 2011; 43: 1010-1013

[2] Levy M], Abu DayyehBK, Fujii LL et al. Detection of peritoneal carcinomatosis by EUS fine-needle aspiration: impact on staging and resectability (with videos). Gastrointest Endosc 2015; 81: 1215-1224
[3] Rana SS, Bhasin DK. EUS: A panacea for detection of peritoneal carcinomatosis! Gastrointest Endosc 2015; 81: 1225-1227

[4] Laing FC, Allison SJ. US of the ovary and adnexa: to worry or not to worry. Radiographics 2012; 32: 1621-1639. discussion 16401642

\section{Bibliography}

Endoscopy 2022; 54: E22-E23

DOI 10.1055/a-1353-4637

ISSN 0013-726X

published online 19.2.2021

(c) 2021. Thieme. All rights reserved.

Georg Thieme Verlag KG, Rüdigerstraße 14, 70469 Stuttgart, Germany

\section{ENDOSCOPY E-VIDEOS}

https://eref.thieme.de/e-videos

回回 Endoscopy E-Videos is a free 鳟 access online section, reporting 靣解: on interesting cases and new techniques in gastroenterological endoscopy. All papers include a high quality video and all contributions are freely accessible online.

This section has its own submission website at https://mc.manuscriptcentral.com/e-videos 